\title{
COMENTARIO A La SENTENCIA DICTADA POR EL Tribunal Constitucional en la CAUSA Rol 6447- 19 DE FECHA 31 DE MAYO DE 2019, QUE DECLARA INADMISIBLE REQUERIMIENTO DE INAPLICABILIDAD POR INCONSTITUCIONALIDAD DEL ESTATUTO MILITAR INTERNACIONAL DE NUREMBERG
}

+[Commentary of the sentence case 6447-19, issued by the Constitutional Court on May 31th, 2019, that declares inadmissible the requirement of inapplicability based in the unconstitutionality of the Nuremberg International Military Statue]

\section{Andrea Rosario Iñiguez Manso*}

Recibido el 20 de junio de 2019 y Aprobado el 14 de agosto de 2019

\section{INTRODUCCIÓN}

Con fecha 30 de mayo de 2019, don Edwin Armando Dimter Bianchi, interpuso requerimiento de inaplicabilidad por inconstitucionalidad del Estatuto Militar del Tribunal Internacional Nuremberg. Ello, porque dicho documento habría servido de fundamento para que el Ministro en Visita de la Corte de Apelaciones, Miguel Vásquez Plaza, lo condenara en la causa rol 16.370-2005, por el secuestro y homicidio simple de los señores Víctor Jara y Litré Quiroga, hechos acaecidos en septiembre de 1973. La Primera Sala declaró la causa a trámite y, habiéndose notificado a todas las partes, declaró el requerimiento inadmisible, toda vez que este no estaría dirigido en contra de un precepto que tenga rango legal, requisito exigido por el artículo $84 \mathrm{~N}^{\circ} 4$ de la Ley $\mathrm{N}^{\circ} 17.997$, Orgánica Constitucional del Tribunal Constitucional (cons. $\left.8^{\circ}\right)^{1}$.

El requerimiento presentaba ciertas particularidades que nos parecen interesantes destacar y que serán objeto del análisis del presente trabajo. En primer lugar, llama la atención que se interponga un requerimiento de inaplicabilidad en contra de un documento internacional que ha servido

* Abogada, Doctora en Derecho por la Universidad de los Andes, Santiago de Chile. Profesora de Derecho Constitucional en las Universidades de los Andes y Autónoma de Chile. Correo electrónico: rosarioini@gmail.com

${ }^{1}$ Tribunal Constitucional, rol 6447-19, sentencia de fecha 31 de Mayo de 2019. 
de base para dictar normativas internacionales e internas en materia de crímenes contra la humanidad. La pregunta es si un texto que reviste tales características puede ser impugnado por la vía de la inaplicabilidad, sobre todo si éste habría sido utilizado para fundamentar la sentencia que se dictó en la gestión pendiente.

En segundo lugar, si bien el requerimiento fue declarado inadmisible por la unanimidad de la Primera Sala, es menester hacer presente que hubo dos votos particulares. El primero fue el de los Ministros Romero, Aróstica y Vásquez y que se refieren al uso de documentos internacionales como mecanismos para fundar las sentencias dictadas por nuestro sistema judicial, y por otra, tenemos la prevención de la Ministra Silva y el Ministro Hernández, quienes sostuvieron que la inadmisibilidad del requerimiento no solo se basa en el artículo 84 de la Ley Orgánica del Tribunal Constitucional, sino también porque el Estatuto impugnado no fue decisivo en el fallo dictado por el Ministro en Visita, y por lo tanto el requerimiento no cumplía con el requisito del artículo $84 \mathrm{~N}^{\circ} 5$ de la misma ley.

Por lo tanto, hacemos presente que en este artículo haremos un análisis sobre el requerimiento en cuanto a los requisitos que exige la Constitución y la Ley 17.997 para que éste pueda ser declarado admisible, y si el requerimiento rol 6447 cumplía o no con tales condiciones. También comentaremos la sentencia y los votos particulares indicados anteriormente. Por lo tanto, no haremos referencia a los contenidos de fondo, tales como los elementos y características de los delitos de lesa humanidad. Tampoco analizaremos si la conducta del requirente puede ser subsumida en dichos tipos penales, ni ahondaremos en el problema de la aplicación del Decreto Ley 2.191 de 1978 (Ley de Amnistía).

\section{EL REQUERIMIENTO}

Con fecha 29 de junio de 2018 el Ministro de Fuero de la Corte de Apelaciones de Santiago dictó sentencia de primera instancia en la cual condenó al requirente, Edwin Dimter Bianchi, a la pena de quince años y un día por el delito de homicidio calificado de Litre Abraham Quiroga Carbajal y Víctor Lido Jara Martínez y a la pena de tres años de presidio menor en su grado medio como autor de secuestro simple de los señores antes mencionados. Estas condenas se fundamentaban en hechos acaecidos en el Estadio Chile desde el 12 de septiembre de 1973. Contra dichas sentencias, se presentaron recursos de apelación y casación en la forma y en el fondo, según constaba en el certificado que daba cuenta de la gestión pendiente que se acompañó al requerimiento. 
a) El requirente reclamó que la sentencia lo condenó a los delitos antes señalados se fundó en el Estatuto Militar del Tribunal Internacional de Nuremberg, que fue firmado por los Aliados en Londres una vez terminada la Segunda Guerra Mundial, y que sirvió de base para los procesos que se celebraron en Nuremberg, y establecieron los delitos de Guerra de Agresión, Crímenes de Guerra y Crímenes contra la Humanidad. Este documento habría sido utilizado por el Juez de Fuero para no aplicar la prescripción de los delitos que se le imputan en autos, la cual habría ocurrido en 1988, como lo indica el considerando décimo tercero bis del fallo en el cual el magistrado sanciona que "Que por último, los delitos antes referidos ${ }^{2}$ serán calificados como delitos de Lesa Humanidad, primeramente al tenor de lo dispuesto en el artículo $6^{\circ}$ del Tribunal Militar Internacional de Nuremberg, en el cual se explicita en su letra c) que constituyen crímenes contra la humanidad"3. Además, hace presente, en el considerando octogésimo, que la ley $\mathrm{N}^{\circ} 20.357$, dictada en 2009, tipificó los Crímenes de Guerra y de Lesa Humanidad, y que "se calificó como delito de Lesa Humanidad los ilícitos perpetrados en autos de acuerdo a lo establecido en el Estatuto del Tribunal Militar Internacional de Nuremberg, que se encuentra incorporado en nuestra legislación de la época y a consecuencia de su carácter imprescriptible, conforme a lo ya razonado en el presente fallo".

b) El requirente sostuvo que la Convención sobre Imprescriptibilidad de los Crímenes de Guerra y de Lesa Humanidad, de 1968, "nunca fue ratificada por el gobierno chileno's y que en nuestro país los crímenes de Lesa Humanidad y Genocidio y Crímenes y Delitos de Guerra fueron tipificados en el año 2009, a través de la Ley $N^{\circ} 20.357$, que estableció además la imprescriptibilidad de dichos delitos, pero que dichas sanciones no pueden operar con efecto retroactivo. En cuanto a los derechos constitucionales vulnerados, se habría afectado el artículo $6^{\circ}$ y el $19 \mathrm{~N}^{\circ}$ 3 en cuanto al derecho que tiene toda persona a que las leyes establezcan reglas para un proceso racional y justo. Además, se vulneraría el principio de legalidad de la conducta penal y de la pena.

c) Pero la cuestión más importante a dilucidar en este requerimiento era si el Estatuto impugnado cumplía con el requisito de tratarse de un precepto legal. En este sentido, el requirente señaló en la primera parte de

${ }^{2}$ Se refiere a los crímenes de Jara y Quiroga.

${ }^{3}$ Sentencia dictada en el proceso de fuera Rol 16.379-2005, seguido ante el Ministro de Fuero de la Corte de Apelaciones, señor Miguel Vázquez Plaza, de fecha 29 de junio de 2018 , cons. $13^{\circ}$ bis.

${ }^{4}$ Sentencia dictada en el proceso de fuera Rol 16.379-2005, cit., cons. $80^{\circ}$.

${ }^{5}$ Tribunal Constitucional, rol 6447-19, cit., fs. 4. 
su requerimiento que el documento impugnado no ha sido incorporado al derecho interno conforme al proceso de formación de las leyes ${ }^{6}$. Pero en el mismo libelo se solicitaba que el Tribunal Constitucional declarare la inaplicabilidad del documento por infringir la Constitución ${ }^{7}$. Esto, en apariencia podría parecer una contradicción, cual es, el hecho de solicitar la inaplicabilidad de un precepto legal que no existe en nuestro ordenamiento jurídico. A ello, la parte requirente respondió que la expresión precepto legal no podía ser entendida en un sentido positivo estricto, sino que, en un sentido más amplio, en cuanto a que en la gestión pendiente al documento impugnado efectivamente se le dio el carácter de precepto legal. Solicitaba que el Tribunal Constitucional pronunciara si vulneraba o no el espíritu de la Carta Fundamental el hecho de que una sentencia judicial tenga como fundamento "el construir una condena criminal aplicando para ello un precepto legal inexistente".

\section{LAS PARTES EN LA GESTIÓN PENDIENTE QUE SE HACEN PARTE EN EL} REQUERIMIENTO

Se hacen partes en el requerimiento los familiares de las víctimas y la Unidad Programa de Derechos Humanos de la Subsecretaría de Derechos Humanos. En distintos escritos, ambos solicitaron a la Sala que declarare inadmisible el requerimiento en atención a los siguientes motivos:

a) No se estaba impugnando un precepto legal. El tratado internacional no constituye precepto un legal, por lo tanto, no puede ser objeto de un requerimiento de inaplicabilidad. Señalaron que "si se privara de eficacia un tratado internacional, por procedimientos del derecho interno, se estarian vulnerando diversos preceptos del Derecho Internacional y comprometiendo la responsabilidad del Estado chileno" . Por lo demás, el documento impugnado en el requerimiento, junto con no constituir un tratado internacional, era un instrumento jurídico importante porque "configura uno de los primeros elementos de la costumbre internacional que mandata la investigación, juzgamiento y sanción de los crimenes de lesa humanidad"10. Es decir, el Ministro de Fuero habría usado normas de ius cogens para resolver el caso y, por lo tanto, era entendible que hubiera utilizado el Estatuto del Tribunal Militar Internacional de Nuremberg para fundar la sentencia. Es más, el contenido del Estatuto "es una norma imperativa de

\footnotetext{
${ }^{6}$ Tribunal Constitucional, rol 6447-19, cit., fs. 3.

${ }^{7}$ Tribunal Constitucional, rol 6447-19, cit., fs. 5.

${ }^{8}$ Tribunal Constitucional, rol 6447-19, cit., fs. 442.

${ }^{9}$ Tribunal Constitucional, rol 6447-19, cit., fs. 422.

${ }^{10}$ Tribunal Constitucional, rol 6447-19, cit., fs. 423.
} 
derecho internacional y su contenido es consustancialmente es indisponible, inderogable, imprescriptible e inamnistiable para nuestro pais. Circunstancia por la cual, resulta evidente que el referido convenio internacional debe ser asimilado a la categoría normativa de tratado internacional"1.

b) La parte requirente impugnaba un documento de manera "abstracta $y$ universal" 12 y el requerimiento de inaplicabilidad tiene por objeto declarar la inaplicabilidad en un caso concreto, es decir, no se cumplía con el artículo $84 \mathrm{~N}^{\circ} 5$ de la Ley Orgánica Constitucional del Tribunal Constitucional. La inaplicabilidad no se puede utilizar para impugnar un tratado internacional de forma general. Por lo demás, el Estatuto del Tribunal Militar Internacional de Nuremberg no fue la única norma que el Ministro de Fuero tuvo en vista para dictar sentencia condenatoria en contra de la parte requirente ${ }^{13}$.

c) Hicieron presente además que el requerimiento no cumple con el artículo $84 \quad \mathrm{~N}^{\circ} 6$ en cuanto a que carece de fundamento. En este punto, el verdadero objetivo del requerimiento era impugnar una resolución judicial que le ha agraviado, y que el requerimiento de inaplicabilidad no era la vía idónea para llevar a efecto tal cometido, sino que la utilización de los recursos que las leyes otorgan para recurrir las sentencias judiciales, los cuales están plenamente disponibles para el requirente en las instancias judiciales pertinentes ${ }^{14}$.

\section{INADMISIBILIDAD}

Con fecha 31 de mayo de 2019, la Primera Sala resolvió por unanimidad rechazar el requerimiento de autos. Ello, porque "para sortear tal requisito de admisibilidad no basta con que la norma objeto de impugnación consista en una regla jurídica sino que también aquella ha de encontrarse determinada y detentar la jerarquia de ley propiamente tal. Ninguno de tales requisitos se satisfacen en la especie, pues según consta a fojas 5, el requirente no ha impugnado normas determinadas sino que la totalidad de un cuerpo normativo, que, por lo demás, escapa al sentido y alcance de la expresión 'precepto legal' en los términos razonados por la jurisprudencia de esta Magistratura constitucional" (cons. $11^{\circ}$ ).

\footnotetext{
${ }^{11}$ Tribunal Constitucional, rol 6447-19, cit., fs. 434.

${ }^{12}$ Tribunal Constitucional, rol 6447-19, cit., fs. 424.

${ }^{13}$ Tribunal Constitucional, rol 6447-19, cit., fs. 436.

${ }^{14}$ Tribunal Constitucional, rol 6447-19, cit., fs. 438 y 439.
} 
La sentencia fue aprobada con dos prevenciones. La primera corresponde a la de los Ministros Aróstica, Romero y Vásquez, quienes hicieron presente, que de la sentencia condenatoria se podía concluir que el Estatuto Internacional del Tribunal Militar de Nuremberg tuvo relevancia para condenar al requirente por los delitos que se contienen en dicho documento $\left(\mathrm{N}^{\circ} 2\right)$. Hicieron presente que la búsqueda de la justicia para delitos que se hubieren cometido en el pasado en nuestro país exige de todas maneras que se respeten "las garantías constitucionales $y$ legales vigentes. En tal sentido, la inexistencia de un texto legal que reconozca una determinada calificación de una conducta típica no puede pretender ser salvada mediante la aplicación de un cuerpo de carácter internacional cuya razón de ser-por antecedentes históricos dista de la situación que se juzga en la especie" ( $\left.\mathrm{N}^{\circ} 4\right)$.

La Ministra Silva y el Ministro Hernández suscribieron la segunda prevención de la resolución de inadmisibilidad, y señalaron que la sentencia definitiva que condenó a la parte requirente por los delitos indicados en la ella no se sustentó solamente en el Estatuto Internacional del Tribunal Militar de Nuremberg, sino que a ello se debía agregar "el artículo $7^{\circ}$ del Estatuto de Roma de la Corte Penal Internacional, como también en la jurisprudencia de la Corte Suprema" (N³) ${ }^{15}$. Por lo demás, el requerimiento estaría siendo utilizado para impugnar una resolución judicial $\left(\mathrm{N}^{\circ} 8\right)$ y que además la parte requirente no señaló la forma en que el texto impugnado infringe la normativa constitucional, y por lo tanto se configuraba "un reproche abstracto de constitucionalidad" $\left(\mathrm{N}^{\circ} 10\right)$.

\section{ANÁLISIS CRÍTICO DE LA SENTENCIA Y DE LOS DOS VOTOS PARTICULARES}

\section{El contenido de la sentencia}

Tal como se ha venido sosteniendo, la Primera Sala del Tribunal Constitucional declaró la inadmisibilidad del requerimiento porque el Estatuto Internacional del Tribunal Militar de Nuremberg no constituía un precepto legal. De hecho, la Sala resolvió que la voz precepto legal "equivale a norma jurídica con rango legal, que puede estar contenida en una parte en todo un artículo o en varios en que el legislador agrupa las disposiciones de una ley" (cons. 10²).

${ }^{15}$ Sentencia dictada en el proceso de fuera Rol 16.379-2005, seguido ante el Ministro de Fuero de la Corte de Apelaciones, señor Miguel Vásquez Plaza, cit., cons. 13 bis. 
Ahora bien, en el supuesto que el mencionado Estatuto hubiera sido aprobado por el Congreso, hubiese sido ratificado por Chile y que se encuentre vigente, sería menester hacerse la siguiente pregunta: ¿los tratados internacionales, pueden ser o no objeto del requerimiento de inaplicabilidad? La Primera Sala omitió referirse a esta cuestión, tal como se indica en el considerando $10^{\circ}$. Cabe hacer presente que los abogados de las partes querellantes en la gestión pendiente señalaron en sus traslados previo a la declaración de admisibilidad, que los tratados internacionales no constituyen precepto legal ${ }^{16}$.

Con respecto a este punto, la jurisprudencia del Tribunal Constitucional no ha sido uniforme. Cabe recordar que el proyecto de ley de reforma a la Ley Orgánica del Tribunal Constitucional aprobado en 2009 por el Congreso, establecía en su artículo 47 B que no procedería el requerimiento de inaplicabilidad en contra las disposiciones de un tratado internacional. Dicho precepto fue declarado inconstitucional por el Tribunal Constitucional cuando dictó sentencia en el uso de sus facultades establecidas el artículo $93 \mathrm{~N}^{\circ} 1$ de la Carta Fundamental. En dicho fallo, dictaminó que excluir al "requerimiento de inaplicabilidad a los preceptos de un tratado internacional, según se declarará, es contraria a la Constitución" (cons. 55) ${ }^{17}$. Tres años más tarde, esta Magistratura resolvió sobre la solicitud de inaplicabilidad de los artículos $22 \mathrm{~N}^{\circ} 2$ y 25 de la Convención de Varsovia ${ }^{18}$. El requerimiento había sido declarado admisible por la Segunda Sala, sin que hubiera prevenciones de algún Ministro en cuanto a que la norma objeto de la impugnación no constituía precepto legal. En contra, en 2015 la Primera Sala declaró inadmisible un requerimiento de inaplicabilidad por inconstitucionalidad del precepto de un tratado internacional, específicamente el artículo 14, párrafo 3 de la Convención de los Derechos del Niño y estableció que "una norma de un tratado internacional ratificado por Chile no constituye 'precepto legal', en términos tales que pueda promoverse a su respecto una acción de inaplicabilidad"19 (cons. $7^{\circ}$ ).

La cuestión de la inaplicabilidad por inconstitucionalidad de los tratados tampoco ha sido pacífica en la doctrina. Así, algunos autores han declarado que no se puede requerir de inaplicabilidad por inconstitucionalidad de un tratado internacional, toda vez que ello puede

${ }^{16}$ Tribunal Constitucional, rol 6447-19, cit., fs.420-422, y fs. 434.

${ }^{17}$ Tribunal Constitucional, rol 1288-08, sentencia de fecha 25 de agosto de 2009.

${ }^{18}$ Tribunal Constitucional, rol 1307-09, sentencia de fecha 20 de enero de 2011.

${ }^{19}$ Tribunal Constitucional, rol 2789-15, sentencia de fecha 25 de marzo de 2015. 
comprometer la responsabilidad internacional de Chile ${ }^{20}$. Por lo demás, la Convención de Viena sobre los tratados no lo permitiría ${ }^{21}$. En contra, otros han sostenido que no se oponen a la posibilidad de que un tratado internacional pueda ser objeto de un requerimiento de inaplicabilidad, por una parte, porque la inaplicabilidad tiene como consecuencia declarar que un precepto legal no podrá tener efecto en un caso concreto, y no se deroga el tratado de manera general y unilateral ${ }^{22}$. Por otra parte, y siguiendo la doctrina asentada por la jurisprudencia Tribunal Constitucional en 2009, si se acepta que los tratados internacionales no puedan ser recurridos por la vía de la inaplicabilidad, se pondría en peligro la supremacía constitucional ${ }^{23}$ y no se puede aceptar que el Estado apruebe un tratado inconstitucional ${ }^{24}$.

\section{Voto particular de los Ministros Aróstica, Romero y Vásquez}

Tal como hemos dicho, estimamos que es necesario comentar los votos particulares de la resolución. La primera corresponde a los Ministros Aróstica, Romero y Vásquez quienes manifestaron que de los antecedentes de la gestión pendiente, y que se acompañó en autos, se podía concluir que el Estatuto Internacional del Tribunal Militar de Nurembeg sirvió para fundar la sentencia dictada por el Ministro en Visita, en particular para imputarle a la parte requirente los delitos contra la humanidad $\left(\mathrm{N}^{\circ} 2\right)$. Además, el mismo Magistrado reconoció en el considerando ochentavo del fallo que dichos delitos recién se tipificaron en nuestro sistema jurídico en la Ley No 20.357 que se dictó en 2009, es decir, con posterioridad a los hechos que dan origen a la sentencia $\left(\mathrm{N}^{\circ} 3\right)$.

Los Ministros hicieron un llamado de atención a la forma que ha

${ }^{20}$ PeÑA TORRes, Marisol, La reforma constitucional de 2005 en materia de tratados internacionales en Revista del Instituto de Estudios Internacionales, $\mathrm{N}^{\circ} 151$ (2005), p. 49. En un mismo sentido ver en: HenríqueZ Viñas, Miriam, Improcedencia del control represivo de constitucionalidad de tratados internacionales, en Estudios Constitucionales 5 (2007), 1, p. 122.

${ }^{21}$ García Barzelatto, Ana María, Informe en derecho. Controlde constitucionalidad de los tratados internacionales con especial referencia al control represivo, en Estudios Constitucionales 5 (2007), 1, p. 478.

${ }^{22}$ NúNEZ PoBlete, Manuel, Las representaciones internas del Derecho Internacional. Control preventivo e inaplicabilidad de los tratados internacionales en la jurisprudencia del Tribunal Constitucional, en Marshall Barberán, Pablo (coord.), Jurisprudencia constitucional destacada (2008-2009) (Santiago, LegalPublishing, 2011), p. 34.

${ }^{23}$ Verdugo Ramírez, Sergio, ¿Control obligatorio para todos los tratados internacionales? Critica a una propuesta inconveniente, en Anuario de Derecho Público UDP (Santiago, Ediciones Universidad Diego Portales, 2010), p. 467.

${ }^{24}$ Bruna Contreras, Guillermo, Los tratados internacionales en la Constitución de 1980. Jurisprudencia en la década de 1981-1989, en Ius et Praxis 9 (2003), 1, p. 339. 
procedido el Ministro en Visita y una crítica de fondo a la sentencia, señalando que si bien era necesario juzgar hecho delictivos acaecidos en nuestro país en el pasado, dichos procedimientos se debían llevar a cabo con respeto "a las garantías constitucionales y legales. En tal sentido, la inexistencia de un texto legal que reconozca una determinada calificación de una conducta típica no puede pretender ser salvada mediante la aplicación de un cuerpo internacional" $\left(\mathrm{N}^{\circ} 4\right)$. En consecuencia, el Estatuto Internacional del Tribuna Militar de Nuremberg no podía ser utilizado para tipificar un delito, ya que vulnera el $19 \mathrm{~N}^{\circ} 3$ de la Carta Fundamental ( $\left.\mathrm{N}^{\circ} 7\right)$. El ius cogens puede ayudar a provocar una regulación de conductas delictuosas, pero que "no resultan una vía de sustitución y reemplazo de la legislación nacional vigente" $\left(\mathrm{N}^{\circ} 8\right)$.

En conclusión, hicieron presente que cuando se juzga una causa, se debe llevar a cabo de la forma más imparcial posible. "El cumplimiento de este deber de imparcialidad obliga a una mayor rigurosidad y cuidado en las argumentaciones que sustentan la decisión del asunto controvertido sometido a su conocimiento del juez, y es precisamente en este sentido que estos Ministros efectúan la presente prevención" $\left(\mathrm{N}^{\circ} 10\right)$.

Como se puede apreciar, los Ministros, que si bien habían declarado la inadmisiblidad del requerimiento por no ser objeto de éste una norma que tenga el rango de precepto legal, de todas maneras se hicieron cargo de otras alegaciones que se habían llevado a cabo en el requerimiento, sobre todo en cuanto a los fundamentos jurídicos que utilizó el Ministro en Visita para condenar el requirente por crímenes contra la humanidad. Como se puede ver, el tenor de las alegaciones hechas por los Ministros son similares a lo que podría ser el contenido de una sentencia de segunda instancia o de casación. Incluso los mismos Ministros que suscribieron el primer voto particular, hicieron un llamado de atención en cuanto a la falta de parcialidad en que habría incurrido el tribunal de instancia.

El mismo Tribunal Constitucional ha dicho en diversas sentencias que éste no es una Magistratura en la cual se puede impugnar resoluciones judiciales. Así, en la causa rol 493-06, se declaró la inadmisibilidad de un requerimiento de inaplicabilidad fundado en que el Tribunal Constitucional no era la instancia idónea para "impugnar resoluciones judiciales de tribunales ordinarios o especiales con la finalidad de revocar, enmendar, casar o anular éstas" (cons. 6) ${ }^{25}$. De igual forma resolvió en la causa rol 5797-18, dictada doce años más tarde, y en la cual volvió a reiterar la doctrina de esta Magistratura en cuanto a que el requerimiento

${ }^{25}$ Tribunal Constitucional, rol 493-06, sentencia de fecha 29 de abril de 2006. 
de inaplicabilidad por inconstitucionalidad no podía ser utilizado para impugnar una resolución judicial, ya que en ese caso en particular, el requerimiento estaría siendo utilizado para reclamar contra un presunto "error de redacción de los Ministros de la Tercera Sala de la Corte Suprema" (cons. 15) ${ }^{26}$.

En definitiva, estos Ministros aceptan por una parte, que no puede declararse admisible el requerimiento ya que su objeto no es un precepto legal y además el requerimiento de inaplicabilidad no se puede usar para impugnar sentencias judiciales, pero por otra parte, en el voto de prevención llevaron a cabo observaciones sobre el fondo de la sentencia de primera instancia. Evidentemente, no se pretendía dejar sin efecto una resolución judicial y actuar como tribunal de instancia, pero de todas maneras se permitieron criticar la forma en que había actuado otro poder del Estado, en este caso, un Ministro en Visita. En todo caso, no sería la primera vez que el Tribunal Constitucional utiliza un fallo para insinuar recomendaciones a otro poder del Estado. Así, en el denominado caso catalíticos, reconoció que existían vacíos legales que permitían que se autorice la restricción vehicular en casos de preemergencia por la vía de la Potestad Reglamentaria. Si bien dicha Magistratura rechazó el requerimiento, declaró que "insta a los poderes Colegisladores a llenar el vacio en esta materia" (cons.47) ${ }^{27}$. Es decir, el voto de mayoría llamó la atención a otros poderes del Estado en cuanto a las necesarias reformas que debería llevar a cabo en materias de ley medio ambiental.

\section{Voto particular de la Ministra Silva y el Ministro Hernández}

La Ministra Silva y el Ministro Hernández hicieron presente que el requirente estaba tratando de impugnar una resolución judicial a través de un requerimiento de inaplicabilidad, el cual no era la vía idónea para conseguir tal fin ( $\mathrm{N}^{\circ} 8$ y 9). Además, estos Ministros previnieron que, en su opinión, el Estatuto del Tribunal Militar Internacional de Nuremberg no fue decisorio en la sentencia dictada por el Ministro en Visita, toda vez que ella se encontraba fundada en otros razonamientos, tales como "el artículo $7^{\circ}$ del Estatuto de Roma de la Corte Penal Internacional" ( $\left.{ }^{\circ} 4\right)$, tal como lo señala el considerando décimo tercero bis de la sentencia del magistrado del fuero que señala que: "En efecto, cabe encuadrar estos ilícitos en este tipo de delitos de Lesa Humanidad, máxime si se observan los elementos de éstos, descritos por el artículo séptimo del Estatuto de Roma que tiene igualmente

${ }^{26}$ Tribunal Constitucional, rol 5794-18, sentencia de fecha 21 de diciembre de 2018.

${ }^{27}$ Tribunal Constitucional, rol 325-01, sentencia de fecha 26 de junio de 2001. 
aplicación en la materia, entregando una definición para los mismos"28.

Es menester recordar brevemente la forma en que se aprobó en Chile el Estatuto de Roma que creó la Corte Penal Internacional. En 2002 esta misma Magistratura declaró que tal tratado, cuya aprobación se estaba tramitando en el Congreso, era inconstitucional. Los fundamentos de tal sentencia no serán analizados en el presente artículo, pero es necesario destacar que una de las razones por la cual se estimó que el tratado en cuestión adolecía de tal vicio, era que su artículo 17 permite a la Corte Penal atribuirse la competencia de conocer de cuestiones cuando estime que el Estado no ha investigado los delitos contra la humanidad o no muestra intención de hacerlo. En relación a ello, el Tribunal Constitucional dictaminó que la Constitución autoriza a determinadas autoridades a otorgar indultos y amnistías (cons. 78). En definitiva, la Corte podría dejar sin efecto indultos o amnistías que habría sido otorgados conforme a la legislación chilena, y que ello constituía una infracción a la Carta Fundamental (cons. 79) 29 .

Así las cosas, en 2009 el Congreso de Chile aprobó la Ley $\mathrm{N}^{\circ}$ 20.352, que agregó a la Carta Fundamental el artículo 24 de las nuevas disposiciones transitorias y en la cual Chile le reconoció competencia a la Corte Penal Internacional. Sin embargo, el inciso $3^{\circ}$ señala que "La jurisdicción de la Corte Penal Internacional, en los términos previstos en su Estatuto, sólo se podrá ejercer respecto de los crímenes de su competencia cuyo principio de ejecución sea posterior a la entrada en vigor en Chile del Estatuto de Roma". Es decir, la Carta Fundamental establece que los preceptos del Estatuto no pueden aplicarse con efecto retroactivo. Además, ello quedó claro durante la tramitación de la ley ${ }^{30}$.

\section{CONCLUSIONES}

El objeto del presente artículo ha sido comentar la resolución dictada por la Primera Sala del Tribunal Constitucional, y que declaró inadmisible el requerimiento de inaplicabilidad por inconstitucionalidad del Estatuto Militar Internacional del Tribunal de Nuremberg y las dos prevenciones que se incluyeron en dicho fallo.

En nuestra opinión, la Primera Sala acertó cuando sostiene que el

${ }^{28}$ Sentencia dictada en el proceso de fuera Rol 16.379-2005, cit., cons. $13^{\circ}$ bis.

${ }^{29}$ Tribunal Constitucional, rol 346-02, sentencia de fecha 8 de abril de 2002.

${ }^{30}$ Historia de la Ley $N^{\circ} 20.352$ en: Biblioteca del Congreso Nacional, disponible [en línea]: https://www.bcn.cl/historiadelaley/nc/historia-de-la-ley/4767/, consultada el 11 de junio de 2019. 
Estatuto impugnado en autos no constituye un precepto legal, toda vez que se trata de un documento internacional que ha servido para dictar tratados internacionales como la Convención para la Prevención y Sanción del Genocidio, Resolución 217 de 1948 de la Asamblea General la cual fue aprobada por Chile en $1953^{31}$ y la Convención contra la Tortura y otros Tratos o Penas Crueles, Inhumanos o Degradantes, aprobada por la Asamblea General, a través de la Resolución 39/46 de 1984, la cual fue aprobada por Chile en $1988^{32}$.

No siendo el Estatuto Militar en cuestión un precepto legal, tampoco podría, en consecuencia, ser utilizado para fundar una sentencia judicial, y menos una de tipo penal. Ello porque éstas deben cumplir con una serie de requisitos que exigen nuestra Constitución, tales como el artículo 19 $N^{\circ} 3$ inc. $7^{\circ}$ en cuanto a que ninguna persona puede ser condenada por un delito que no está tipificado al momento de cometerse el delito. Lo mismo pasa con el principio de legalidad de la pena (inc. $8^{\circ}$ ). Además, la Convención Americana de Derechos Humanos, en igual sentido, señala que en su artículo $9^{\circ}$ "Nadie puede ser condenado por acciones $u$ omisiones que en el momento de cometerse no fueran delictivos según el derecho aplicable. Tampoco se puede imponer pena más grave que la aplicable en el momento de la comisión del delito cuando la ley dispone la imposición de una pena más leve, el delincuente se beneficiará de ello".

Por lo tanto, coincidimos en este punto con el contenido de la prevención de los Ministros Aróstica, Vásquez y Romero en cuanto a las infracciones a las constitucionales en las cuales incurre el fallo del Ministro en Visita. En todo caso, estimamos que no es función del Tribunal Constitucional, ni por voto de mayoría ni en prevenciones, llevar a cabo observaciones a las cuestiones de fondo de la sentencia que constituye la gestión pendiente del requerimiento. Como se ha dicho, el mismo fallo sostiene en el considerando $2^{\circ}$ que el Tribunal Constitucional no es un organismo para revisar resoluciones judiciales y no constituye instancia. A ello se debe agregar que esta Magistratura también ha señalado que no puede llevar a cabo en sus fallos un "mérito político"33. Si bien coincidimos con las cuestiones manifestadas por los Ministros que llevan a cabo la prevención, nos parece que un fallo del Tribunal Constitucional no es la instancia más indicada para manifestarlas.

${ }^{31}$ Decreto 316 del Ministerio Relaciones Exteriores, de fecha de 11 de diciembre de 1953.

${ }^{32}$ Decreto 808 del Ministerio Relaciones Exteriores, de fecha de 23 de diciembre de 1988.

${ }^{33}$ Tribunal Constitucional, rol 4757-18, 19 de julio de 2018, cons. $8^{\circ}$. 
En relación al tema del ius cogens y la posibilidad de dictar una condena penal en base a estos principios, coincidimos con el voto particular de estos Ministros en cuanto a que "no resultan una vía de sustitución y reemplazo de la legislación nacional vigente" ( $\mathrm{N}^{\circ}$ 8). Los principios generales de ius cogens son sólo eso, principios enunciados de forma general, pero que presentan problemas en relación al requisito de legalidad de los tipos penales ${ }^{34}$.

En cuanto al segundo voto particular suscrito por la Ministra Silva y el Ministro Hernández, no estamos da acuerdo en cuanto a que el Estatuto impugnado no haya sido decisivo en la condena dictada por el Ministro de Fuero. Si bien reconocemos que el artículo $7^{\circ}$ del Estatuto de Roma que crea la Corte Penal Internacional también fue utilizado para fundar la sentencia, de todas forma el documento impugnado tuvo relevancia en la sentencia de fondo.

Dos ideas antes de terminar. En nuestra opinión, si el requirente pretendía impugnar ante el Tribunal Constitucional algún precepto legal que sirvió de fundamento para la sentencia de primera instancia, debería haber intentado un requerimiento en contra del artículo $7^{\circ}$ del Estatuto de Roma que crea la Corte Penal Internacional, ya que forman parte de nuestro ordenamiento jurídico, y en nuestra opinión, pueden ser objeto de un requerimiento de inaplicablidad ${ }^{35}$. La segunda reflexión es constatar una práctica poco feliz de los tribunales, tanto nacionales como internacionales, tales como fundar sus sentencias en documentos que no tienen rango legal ni el carácter de tratado internaciona ${ }^{36}$. En cuanto a los tribunales nacionales, ellos solo deberían recurrir a normas que estén

${ }^{34}$ Malarino, Exequiel, Derechos Humanos y derecho penal (Bogotá, Editorial Ibáñez, 2012), p. 218.

${ }^{35}$ Cabe tener presente que el Tribunal Constitucional declaró constitucional el Tratado de Roma que crea la Corte Penal Internacional en 2009 (rol 1415-09). Sin embargo, no hizo un análisis de cada una de las normas del tratado, y utilizó una fórmula general para declararlo constitucional. Así, declaró en la sentencia que el tratado aprobado por el Congreso "no contiene normas orgánico constitucionales contrarió a la Constitución". En consecuencia, no vemos impedimento para que en el futuro no se pudiera presentar un requerimiento de inaplicabilidad de algún precepto del tratado en mención.

${ }^{36}$ Es lo que sucede con el denominado "soft law", práctica muy utilizada por la Corte IADH. Así, a modo de ejemplo se puede mencionar el caso "López Lone y otros v. Honduras” el tribunal utiliza la Observación General No 32 del Comité de Derechos Humanos de la ONU en materias de garantías de estabilidad para los jueces (cons. 161) y en "Hilarie Constantine y Benjamin y otros v. Trinidad y Tobago", la Corte fundó su opinión sobre el debido proceso en la Opinión Consultiva OC16/99(cons.146). 
vigentes en al sistema jurídico nacional conforme a los procedimientos que establece la Constitución y la ley. Y en cuanto a los tribunales internacionales, tales como la Corte IADH, debería fundar sus fallos en la Convención Americana de Derechos Humanos u otros tratados que expresamente, por voluntad de los Estados contratantes y conforme a sus procedimientos legales internos le hubieren reconocido competencia jurisdiccional.

\section{BibLIOGRAFÍA}

Bruna Contreras, Guillermo, Los tratados internacionales en la Constitución de 1980. Jurisprudencia en la década de 1981-1989, en Ius et Praxis 9 (2003), 1.

HenríQuez Viñas, Miriam, Improcedencia del control represivo de constitucionalidad de tratados internacionales, en Estudios Constitucionales 5 (2007), 1.

García Barzelatto, Ana María, Informe en derecho. Control de constitucionalidad de los tratados internacionales con especial referencia al control represivo, en Estudios Constitucionales 5 (2007), 1.

Malarino, Exequiel, Derechos Humanos y derecho penal (Bogotá, Editorial Ibáñez, 2012).

Peña Torres, Marisol, La reforma constitucional de 2005 en materia de tratados internacionales, en Revista del Instituto de Estudios Internacionales 151 (2005).

NúNÉz PoBlete, Manuel, Las representaciones internas del Derecho Internacional. Control preventivo e inaplicabilidad de los tratados internacionales en la jurisprudencia del Tribunal Constitucional, en Marshall Barberán, Pablo (coord.), Jurisprudencia constitucional destacada (2008-2009) (Santiago, LegalPublishing, 2011).

Verdugo Ramírez, Sergio, ¿Control obligatorio para todos los tratados internacionales? Critica a una propuesta inconveniente, en Anuario de Derecho Público UDP (Santiago, Ediciones Universidad Diego Portales, 2010). 